\title{
Do Patients of Chronic Low Back Pain have Psychological Comorbidities?
}

\author{
Santoshi ${ }^{3,}$ \\ ${ }^{1}$ Department of Psychiatry, All India Institute of Medical Sciences, \\ Bhopal, Madhya Pradesh, India \\ ${ }^{2}$ Department of Community and Family Medicine, All India Institute \\ of Medical Sciences, Bhopal, Madhya Pradesh, India \\ ${ }^{3}$ Department of Orthopaedics, All India Institute of Medical \\ Sciences, Bhopal, Madhya Pradesh, India \\ Avicenna J. Med. 2021;3:145-151.
}

Kritika Singhal ${ }^{1}$ Krishna Prasad Muliyala ${ }^{1}$ Abhijit P. Pakhare ${ }^{2}$ Prateek Behera ${ }^{3} \quad$ John Ashutosh

\begin{abstract}
Address for correspondence John Ashutosh, MS (Orth), DNB (Orth), MAMS, Department of Orthopaedics, All India Institute of Medical Sciences, Bhopal, Madhya Pradesh, India (e-mail: jasantoshi@gmail.com).
\end{abstract}

\section{Abstract}

Keywords

- low back pain

- psychological

- comorbidity

- anxiety

- depression

- alexithymia

- insomnia
Background Individuals with chronic pain have been reported to have an increased incidence of psychological morbidities. We aimed to examine the prevalence of anxiety, depression, disability, alexithymia, insomnia, and sleep quality in patients having chronic low back pain (LBP) and study their association with the severity of pain and any disability arising from it.

Methods This descriptive study was conducted in a tertiary care teaching hospital setting. Fifty adults with nonspecific LBP of $>6$-week duration were included. Study instruments employed were patient health questionnaire-9 for depression, generalized anxiety disorder-7 for anxiety, visual analogue scale (VAS) score for pain, Oswestry disability index (ODI) to assess disability, Toronto alexithymia scale-20 for alexithymia, and insomnia severity index and Pittsburgh sleep quality index for insomnia. Descriptive results were expressed as numbers, means, and proportions. Association study between variables was performed using Fisher's exact test.

Results Mean ODI score was 31.54\% (95\% Cl, 26.09-36.99); mean VAS score was 6.08 $(95 \% \mathrm{Cl}, 5.35-6.81)$. Insomnia of varying severity was found in 29 patients. Sleep quality was reported as good by 23 patients. One patient had alexithymia. There was significant association between the level of disability and depression, anxiety, insomnia, and sleep quality. The severity of pain had significant association with insomnia but the association with anxiety, depression, alexithymia, and sleep quality was not significant. Conclusions Patients with chronic LBP do have associated psychological comorbidities of varying extent. A "patient-centric" approach when treating patients with chronic LBP is necessary, so that appropriate evaluation of psychiatric and psychosocial comorbidities, sleep problems, and quality of life is done as part of their routine management to ensure the desired outcomes. published online

September 6, 2021
DOI https://doi.org/

$10.1055 / \mathrm{s}-0041-1734385$

ISSN 2231-0770
(C) 2021. Syrian American Medical Society.

This is an open access article published by Thieme under the terms of the Creative Commons Attribution-NonDerivative-NonCommercial-License, permitting copying and reproduction so long as the original work is given appropriate credit. Contents may not be used for commercial purposes, or adapted, remixed, transformed or built upon. (https://creativecommons.org/licenses/by-nc-nd/4.0/).

Thieme Medical and Scientific Publishers Private Limited A-12, Second Floor, Sector -2, Noida-201301, Uttar Pradesh 


\section{Introduction}

Low back pain (LBP) is a common musculoskeletal impairment experienced by approximately 70 to $85 \%$ of the general population at some point during their lifetime. ${ }^{1}$ While most people experience LBP of a short duration, which improves over time irrespective of the treatment taken, few people fail to get adequate pain relief. ${ }^{2}$ LBP lasting longer than 7 to 12 weeks is often termed as a chronic LBP. ${ }^{1}$ The incidence of chronic LBP has been reported to be around $9 \%$ to $21 \%{ }^{2}$ Chronic LBP is often ranked as a leading cause of disability and inability to work and is a common reason for seeking specialist medical consultations. ${ }^{3}$ From an Indian context, Sharma et al found that joint pain was the commonest musculoskeletal condition observed across three Indian cities, followed by back pain with a prevalence of $7.08 \%, 11.52 \%$ and $9.53 \%$, respectively, at these centers. ${ }^{4}$

While a well-defined underlying cause for pain might not be apparent or identifiable in many individuals, any pain lasting or recurring over a long period of time could be labeled as a chronic pain. ${ }^{1}$ Persistent chronic pain has been suggested to result in a range of structural, functional, and neurochemical changes in the cortical areas of human brain involved in the recognition of emotions, and a close correlation has been suggested between affective pain component and the extent to which these changes occur. ${ }^{5,6}$ The corticolimbic system, comprising the prefrontal cortex, anterior cingulate cortex, amygdala, hippocampus, nucleus accumbens, and periaqueductal gray matter, is a mediator of chronic pain and plays an important role in the development, maintenance, and amplification of chronic pain. ${ }^{7.8}$

Individuals with chronic pain have been reported to have an increased incidence of psychological morbidities like high levels of emotional distress presenting with mood and anxiety symptoms. ${ }^{7,-11}$ For example, studies by Western researchers have documented an increased incidence of anxiety, depression, alexithymia, and disability in patients with chronic LBP. ${ }^{7,12-15}$ Alexithymic individuals experience difficulty in communicating feelings, which may make them to incorrectly interpret signs of emotional arousal as signs of a disease. They may fail to take the comfort of other people, as they have difficulties in communicating their psychological distress. Although there is a high prevalence of alexithymia in many chronic pain conditions, yet the relationship between pain intensity and alexithymia is not firmly established. Sleep impairment has also been reported among these patients and shares a close relationship with pain severity. ${ }^{2,15,16}$

However, little is known about the prevalence of psychological comorbidities with chronic LBP in developing countries, where much of the world's population lives. ${ }^{17,18}$ This descriptive questionnaire-based study aimed to examine the prevalence of anxiety, depression, disability, alexithymia, insomnia, and sleep quality in patients having chronic LBP and study their association with disability and the severity of pain.

\section{Materials and Methods}

We conducted a cross-sectional observational study after obtaining formal approval of the institutional human ethics committee of All India Institute of Medical Sciences (AIIMS), Bhopal, India (LOP/2015/STS0045-2015). The study was conducted over a period of 2 months on patients diagnosed to have nonspecific chronic LBP who were attending the orthopedic outpatient clinic of our institute. The patients underwent investigations like imaging of the lumbosacral spine and blood tests to rule out a structural or infective cause for the LBP. Fifty patients satisfying the inclusion and exclusion criteria were enrolled. Inclusion criteria were 1) age > 18 years and 2) LBP which had failed to improve over past 6 weeks. Patients with LBP of $<6$-week duration, chronic LBP combined with other diagnosed musculoskeletal diseases, patients with history of back surgery, individuals who were incapable of understanding and answering the questionnaires, and those who did not consent were excluded.

Detailed information about the study was provided to all patients before obtaining their consent. Particulars like age, gender, number of family members, occupation, socioeconomic status, marital status, education, requirement for analgesics and sleep medication, substance abuse (alcohol, tobacco products), and preexisting nonmusculoskeletal medical, surgical or psychiatric illness and medications for their treatment were recorded apart from the specific study instruments.

The specific study instruments employed in this study were as follows: patient health questionnaire (PHQ-9), generalized anxiety disorder (GAD-7), Visual Analogue Scale (VAS) score for perception of pain, Oswestry disability index (ODI), Toronto alexithymia scale-20 (TAS-20), insomnia severity index (ISI), and Pittsburgh sleep quality index (PSQI). ${ }^{19-25}$

The severity of depression was assessed using PHQ-9 and graded as none/minimal (0-4), mild (5-9), moderate (10-14), moderately severe (15-19), and severe (20-27). GAD-7 questionnaire includes questions on the seven core symptoms of generalized anxiety, namely, nervousness, inability to stop worrying, excessive worry, restlessness, difficulty in relaxing, easy irritation, and fear of something awful happening. It rates how often the patients were bothered by each of these core symptoms over the past 2 weeks; the scores of the GAD-7 range from 0 to 21. VAS score was used to assess patients' perception of current pain; on a $10 \mathrm{~mm}$ VAS scale, the patients' ratings are graded as no pain (0), mild pain ( 1 to $3 \mathrm{~mm}$ ), moderate pain (4 to $6 \mathrm{~mm}$ ), and severe pain ( 7 to 10$)$. ODI was used to assess the limitations of various activities of daily living; the scores are assessed as minimal disability (0\% to $20 \%$ ), moderate disability $(20 \%$ to $40 \%$ ), severe disability ( $40 \%$ to $60 \%$ ), crippled (60\% to $80 \%$ ), and bedbound or exaggerating ( $80 \%$ to $100 \%$ ). TAS-20 scale was used to assess the level of alexithymia. It consists of 20 items which load on three factors, namely, difficulty in identifying feelings, difficulty in describing feelings, and externally oriented thinking. ISI is used to assess insomnia severity, sleep satisfaction, sleep interference with daytime 
functioning, noticeability of sleep impairment, and distress caused by insomnia over the last 2 weeks; the scores are assessed as no significant insomnia (0 to 7 ), subthreshold insomnia ( 8 to 14 ), moderate insomnia (15 to 21 ), and severe insomnia (22 to 28 ). PSQI was used to evaluate sleep quality over the last 1 month. It consists of 19 items to evaluate the seven aspects of sleep quality (sleep onset latency, sleep

Table 1 Summary of the demographic details of the study participants

\begin{tabular}{|c|c|c|}
\hline \multicolumn{2}{|l|}{ Particulars } & Numbers (\%) \\
\hline \multirow[t]{2}{*}{ Gender } & Male & $23(46 \%)$ \\
\hline & Female & 27 (54\%) \\
\hline \multirow[t]{2}{*}{ Marital status } & Married & $39(78 \%)$ \\
\hline & Unmarried & $11(22 \%)$ \\
\hline \multirow{5}{*}{$\begin{array}{l}\text { Educational } \\
\text { qualification }\end{array}$} & Postgraduation & $3(6 \%)$ \\
\hline & Graduation & $9(18 \%)$ \\
\hline & Matriculation & $10(20 \%)$ \\
\hline & $\begin{array}{l}\text { Higher } \\
\text { Secondary }\end{array}$ & $11(22 \%)$ \\
\hline & $\begin{array}{l}\text { Primary } \\
\text { education }\end{array}$ & 17 (34\%) \\
\hline \multirow[t]{7}{*}{ Occupation } & Homemaker & $16(32 \%)$ \\
\hline & Service & $10(20 \%)$ \\
\hline & Student & $9(18 \%)$ \\
\hline & Farmer & $5(10 \%)$ \\
\hline & Businessman & $3(6 \%)$ \\
\hline & Tailor & $1(2 \%)$ \\
\hline & Retired & $6(12 \%)$ \\
\hline \multirow[t]{2}{*}{ Alcohol intake } & Yes & $8(16 \%)$ \\
\hline & No & $42(84 \%)$ \\
\hline \multirow{2}{*}{$\begin{array}{l}\text { Tobacco product } \\
\text { consumption }\end{array}$} & Yes & $10(20 \%)$ \\
\hline & No & $40(80 \%)$ \\
\hline \multirow{2}{*}{$\begin{array}{l}\text { Frequent need of } \\
\text { pain medications }\end{array}$} & Yes & 31 (62\%) \\
\hline & No & $19(38 \%)$ \\
\hline \multirow{2}{*}{$\begin{array}{l}\text { Frequent need of } \\
\text { sleep medications }\end{array}$} & Yes & $3(6 \%)$ \\
\hline & No & 47 (94\%) \\
\hline
\end{tabular}

Table 2 Table showing the mean scores and the SD of the different study instruments used

\begin{tabular}{|l|l|l|}
\hline Parameter & Mean & SD \\
\hline ODI score & $31.54 \%$ & $19.17 \%$ \\
\hline VAS for pain & 6.08 & 2.56 \\
\hline GAD-7 score & 7.98 & 6.88 \\
\hline PHQ-9 score & 8.82 & 6.59 \\
\hline TAS-20 score & 37.10 & 5.97 \\
\hline ISI score & 9.76 & 6.94 \\
\hline PSQI score & 6.84 & 5.07 \\
\hline
\end{tabular}

Abbreviations: GAD-7, generalized anxiety disorder; ISI, insomnia severity index; ODI, Oswestry disability index; PHQ-9, patient health questionnaire; PSQI, Pittsburgh sleep quality index; TAS-20, Toronto alexithymia scale-20; VAS, visual analogue scale score for perception of pain. duration, efficiency, quality, disturbances, medication, and day-time dysfunction); a higher score indicates poor sleep quality.

All the data was collected in a Microsoft Excel sheet. It was then coded, entered, and analyzed using Statistical Package for Social Science (SPSS version 26, Armonk NY). The descriptive results were expressed as numbers, means, and proportions. Association study between the variables was performed, statistical significance was calculated using Fisher's exact test, and $p$ value of $<0.05$ was taken as statistically significant.

\section{Results}

A total of 78 patients diagnosed with nonspecific chronic LBP were approached during the study period. Of which, 50 who satisfied all the inclusion and exclusion criteria were enrolled. Among these, 23 (46\%) were males and 27 (54\%) were females. The mean age of patients was 42.78 years $( \pm 15.93)$. The level of education was graduation and above for 12 (24\%) patients; 39 patients (78\%) were married. Most patients did not consume alcohol or use tobacco ( $n=42$ and $n=40$, respectively). Frequent requirement of pain-relief medications for the LBP was reported by 31 (62\%) patients. However, only 3 (6\%) participants required frequent sleep-inducing medications. The demographic details of the patients are shown in - Table 1.

The mean ODI score was 31.54\% (95\% CI, 26.09-36.99). Most patients were minimally or moderately disabled but $15(30 \%)$ were either severely disabled or crippled. The mean VAS pain score was 6.08 (95\% CI, 5.35-6.81). Severe LBP was reported by 18 (36\%) patients. Nine (18\%) patients reported no anxiety, while $10(20 \%)$ reported severe anxiety. Moderate-to-severe depression was found in $30(60 \%)$ patients. Insomnia of varying severity was found in 29 (58\%) patients. Sleep quality was reported as good by $23(46 \%)$ patients and an almost equal number $(n=27)$ reported it to be poor. Only one patient possibly had alexithymia. The prevalence of various psychological comorbidities in patients with chronic LBP is shown in - Table 2 and -Fig. 1.

An analysis of the level of disability in relation to other parameters showed a statistically significant association between the level of disability and depression, anxiety, insomnia, and sleep quality. However, no statistically significant association was found between the level of disability with pain severity and alexithymia ( - Table 3 ). Severity of pain had statistically significant association with insomnia $(p=0.021)$ but the association with anxiety, depression, alexithymia, and sleep quality $(P>0.05)$ was not significant $(-$ Table 4$)$.

No statistically significant associations were found (Fisher's exact test) between the patient's gender and any of the studied instruments. While no significant difference in the frequency of consumption of pain-relieving medication and sleep medication was observed between males and females, males consumed alcohol and tobacco much more frequently than females (at the ratios of 7:1 and 8:2, respectively). No significant association was found between consumption of alcohol and tobacco products with 


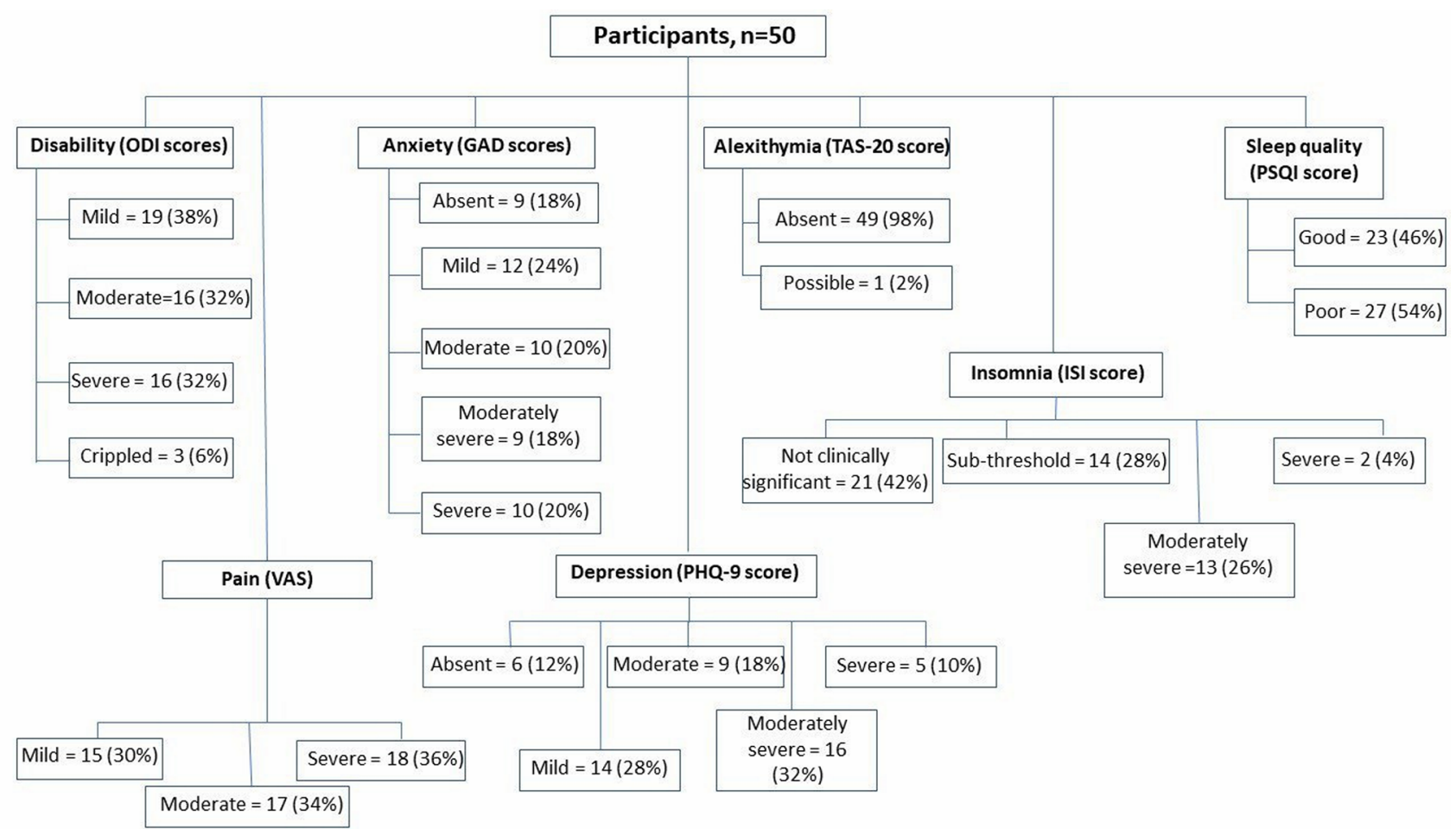

Fig. 1 The number and percent of participants with chronic low back pain (LBP) and various psychological comorbidities.

Table 3 Table showing the association of disability (measured with ODI) with the different psychological comorbidities in study participants

\begin{tabular}{|c|c|c|c|c|c|c|c|c|c|c|c|c|}
\hline \multirow{2}{*}{$\begin{array}{l}\text { Disability } \\
\text { based on } \\
\text { ODI scores }\end{array}$} & \multicolumn{2}{|c|}{ Pain (VAS score) } & \multicolumn{2}{|c|}{ Anxiety } & \multicolumn{2}{|c|}{ Depression } & \multicolumn{2}{|c|}{ Alexithymia } & \multicolumn{2}{|c|}{ Insomnia } & \multicolumn{2}{|c|}{ Sleep quality } \\
\hline & Mild & $\begin{array}{l}\text { Moderate- } \\
\text { to-severe }\end{array}$ & $\begin{array}{l}\text { No } \\
\text { anxiety }\end{array}$ & $\begin{array}{l}\text { Mild-to- } \\
\text { severe } \\
\text { anxiety }\end{array}$ & \begin{tabular}{|l|} 
No \\
depres- \\
sion
\end{tabular} & \begin{tabular}{|l|} 
Mild-to- \\
severe \\
depression
\end{tabular} & $\begin{array}{l}\text { No alex- } \\
\text { ithymia }\end{array}$ & $\begin{array}{l}\text { Possible } \\
\text { alexithymia }\end{array}$ & $\begin{array}{l}\text { No } \\
\text { insomnia }\end{array}$ & $\begin{array}{l}\text { Insomnia } \\
\text { (different } \\
\text { grades) }\end{array}$ & $\begin{array}{l}\text { Good } \\
\text { sleep } \\
\text { quality }\end{array}$ & $\begin{array}{l}\text { Poor sleep } \\
\text { quality }\end{array}$ \\
\hline $\begin{array}{l}\text { Minimal } \\
\text { disability }\end{array}$ & 8 & 11 & 9 & 10 & 5 & 14 & 18 & 1 & 14 & 5 & 15 & 4 \\
\hline $\begin{array}{l}\text { Moderate/ } \\
\text { severe } \\
\text { disability/ } \\
\text { crippled }\end{array}$ & 7 & 24 & 0 & 31 & 1 & 30 & 31 & 0 & 7 & 24 & 8 & 23 \\
\hline $\begin{array}{l}\text { p-value } \\
\text { (Fisher's } \\
\text { exact test) }\end{array}$ & & 0.144 & & 000 & & .015 & & .197 & & 000 & & 0.000 \\
\hline
\end{tabular}

Abbreviations: ODI, Oswestry disability index; VAS, visual analogue scale score for perception of pain.

Table 4 Table showing the association of pain (measured with VAS) with the different psychological comorbidities

\begin{tabular}{|c|c|c|c|c|c|c|c|c|c|c|}
\hline \multirow{2}{*}{$\begin{array}{l}\text { Pain } \\
\text { (based } \\
\text { on VAS } \\
\text { score) }\end{array}$} & \multicolumn{2}{|c|}{ Anxiety } & \multicolumn{2}{|c|}{ Depression } & \multicolumn{2}{|c|}{ Alexithymia } & \multicolumn{2}{|c|}{ Insomnia } & \multicolumn{2}{|c|}{ Sleep quality } \\
\hline & $\begin{array}{l}\text { No } \\
\text { anxiety }\end{array}$ & $\begin{array}{l}\text { Mild- } \\
\text { to- } \\
\text { severe } \\
\text { anxiety }\end{array}$ & $\begin{array}{l}\text { No } \\
\text { depression }\end{array}$ & $\begin{array}{l}\text { Mild-to- } \\
\text { severe } \\
\text { depression }\end{array}$ & $\begin{array}{l}\text { No } \\
\text { alexithymia }\end{array}$ & $\begin{array}{l}\text { Possible } \\
\text { alexithymia }\end{array}$ & \begin{tabular}{l|} 
No \\
insomnia
\end{tabular} & $\begin{array}{l}\text { Insomnia } \\
\text { (different } \\
\text { grades) }\end{array}$ & $\begin{array}{l}\text { Good } \\
\text { sleep } \\
\text { quality }\end{array}$ & $\begin{array}{l}\text { Poor sleep } \\
\text { quality }\end{array}$ \\
\hline Mild pain & 3 & 12 & 2 & 13 & 14 & 1 & 10 & 5 & 9 & 7 \\
\hline $\begin{array}{l}\text { Moderate- } \\
\text { to-severe } \\
\text { pain }\end{array}$ & 6 & 29 & 4 & 31 & 35 & 0 & 11 & 24 & 15 & 20 \\
\hline $\begin{array}{l}\text { p-value } \\
\text { (Fisher's } \\
\text { exact test) }\end{array}$ & \multicolumn{2}{|c|}{0.810} & \multicolumn{2}{|c|}{0.849} & \multicolumn{2}{|c|}{0.123} & \multicolumn{2}{|c|}{0.021} & \multicolumn{2}{|r|}{0.496} \\
\hline
\end{tabular}

Abbreviation: VAS, visual analogue scale score for perception of pain. 
Table $52 \times 2$ table constructed to study the odds of having multiple psychological comorbidities and chronic LBP

\begin{tabular}{|c|c|c|c|c|}
\hline & & \multicolumn{2}{|c|}{ LBP } & \multirow[t]{2}{*}{ Total } \\
\hline & & $\begin{array}{l}\text { Moderate-to-severe pain } \\
(\% \text { of } 35)\end{array}$ & $\begin{array}{l}\text { Mild pain } \\
(\% \text { of } 15)\end{array}$ & \\
\hline \multirow{2}{*}{$\begin{array}{l}\text { Number of psychological } \\
\text { comorbidities }\end{array}$} & $\geq 2$ & 29 (82.9\%) & 12 (80\%) & 41 \\
\hline & $\leq 1$ & $6(17.1 \%)$ & $3(20 \%)$ & 9 \\
\hline \multicolumn{2}{|l|}{ Total } & 35 (70\%) & 15 (30\%) & 50 \\
\hline
\end{tabular}

Abbreviation: LBP, low back pain.

depression, disability level, anxiety, pain, insomnia, sleep quality, and alexithymia.

The odds of a patient of chronic LBP to be depressed and consuming alcohol were 0.94 , while the odds of having anxiety and consuming alcohol were 0.6 . The odds of experiencing moderate-to-severe pain and consuming alcohol were 0.667 . Similarly, the odds of being depressed, having anxiety and being in moderate-to-severe pain, and consuming tobacco products were $0.444,0.848$ and 0.569 , respectively. The odds of having two or more psychological comorbidities and moderate-to-severe back pain (VAS score) was 1.208 ( -Table 5).

\section{Discussion}

In the present study, we found significant association between the levels of disability and depression, anxiety, insomnia and sleep disturbance with chronic LBP. While significant association was found between depression and insomnia with respect to severity of pain, significant association was not found between anxiety, sleep disturbance, alexithymia and severity of pain, and between alexithymia and the level of disability.

Studies in the past have demonstrated the correlation between LBP and psychological comorbidities like anxiety, depression, somatization symptoms, stressful responsibility, job dissatisfaction, mental stress at work, negative body image, ego weakness, and poor drive satisfaction. ${ }^{12,18,26,27}$ Unrecognized and untreated psychopathology can significantly interfere with successful rehabilitation of chronic LBP and also increase pain intensity and disability, thus serving to perpetuate pain-related dysfunction. ${ }^{5}$ Depression and anxiety are barriers to treatment adherence, and improving the mental health conditions have been reported to improve adherence and effectiveness of the treatment. ${ }^{28}$ Therefore, from a clinical perspective, psychological factors are an important domain to assess treatment effectiveness. ${ }^{29}$ Recent studies suggest psychological support and treatment to be important in patients with LBP to minimize depression and anxiety and improve their quality of life. ${ }^{30}$ Biopsychosocial rehabilitation interventions that use a multidisciplinary approach have been reported to be more effective than usual care and physical treatments in decreasing pain and disability in persons with chronic LBP. ${ }^{6,31}$ While studies in the past have looked at multiple coexisting chronic medical conditions, or coexisting pain conditions, we found no study looking at the prevalence of multiple psychological comorbidities in patients with chronic LBP. ${ }^{32,33}$ The prevalence of multiple coexisting psychological comorbidities in our study is shown in - Table 5 .

Hong et al studied depression, anxiety, disability, sleep quality, and quality of life in patients with chronic LBP and found these patients to have considerable functional disability and significant impairment of psychological status with a low quality of life. ${ }^{2}$ We agree with their suggestion of the importance of evaluating and managing the psychosocial illness and impairment of quality of life in patients with chronic LBP, and that these should be a part of the patient's regular follow-up. In a survey conducted among primary health care visitors, Bener et al compared LBP patients to patients without LBP and found a prevalence of psychological distress such as anxiety (9.5\% versus $6.2 \%$ ), depression (13.7\% versus $8.5 \%$ ), and somatization (14.9\% vs. $8.3 \%$ ) in the LBP patients. ${ }^{34}$ Marčić et al studied the prevalence of depression and the relationship between depression and pain intensity in 99 LBP patients. ${ }^{12}$ While general physical symptoms were most common (71\%), they were closely followed by psychic anxiety (70\%) and depressed mood (67\%). They concluded that depression was more severe in LBP patients with severe disease compared with those with mild or moderate disease. Soysal et al compared disability, sleep quality, depression, physical activity level, and quality of life in preoperative chronic LBP patients, chronic LBP outpatients with a healthy control group and found that physical activity level was much more affected than the sleep quality, depression and quality of life parameters in preoperative chronic LBP patients than in others. ${ }^{26}$

Insomnia, the most common sleep disorder, is common in painful conditions and can adversely influence an individual's experience of pain through increasing perception of pain and decreasing pain tolerance and pain threshold. ${ }^{35}$ O'Donoghue et al in an objective and subjective assessment of sleep in chronic LBP reported $87 \%$ participants having poor sleep quality and over half reporting threshold clinical insomnia. ${ }^{16}$ In the present study, 54\% patients reported poor sleep quality and 30\% reported insomnia. Insomnia and poor sleep quality correlated with the severity of pain and level of disability. We agree with Alsaadi et al that given the prevalence of sleep disturbance in patients with chronic LBP and its likely effects like increased fatigue, daytime sleepiness and 
low mood, it would be prudent to ensure that sleep problems are properly assessed and managed in these patients. ${ }^{36}$

We looked for the prevalence of alexithymia as well as its correlation with severity of pain and level of disability in our study sample. The prevalence of alexithymia in our sample (2\%) was much lower than the prevalence rate reported in other studies (14.8 to $22 \%$ ). The lower prevalence was surprising, considering that psychosomatic conditions have been traditionally associated with high rates of alexithymia. The relationship between alexithymia and culture has also been described to be complex. ${ }^{37}$ Alexithymia was not found to correlate with the severity of pain and level of disability in the current study, a finding which was consistent with that of Turesky. ${ }^{38}$ Literature available on alexithymia and disability is scant. As stated previously, the relationship between pain severity and alexithymia is not firmly established. One possible reason could be unidimensional measurement of pain that considers only the sensory component without measuring the affective component. The association is somewhat established in some studies that have measured affective component of pain in addition to sensory component. ${ }^{39} \mathrm{We}$ could not explain this low prevalence of alexithymia in the present study, which could have been due to the small sample size in our study.

\section{Strengths}

We were able to study the prevalence of a few common psychological comorbidities including alexithymia which has not been studied earlier, especially in the Indian context where cultural factors and stigma may be responsible for patients with psychological distress to often present with somatic symptoms. ${ }^{40}$ We recognize the need for a large-scale multicentric study on this important subject and the need for a "patient-centric" approach when treating patients with chronic LBP, so that appropriate evaluation of psychosocial illness, sleep problems, and quality of life is done as part of routine management as well as during follow-up.

\section{Limitations}

We recognize that small sample size, heterogeneous sample, and lack of a control group are limitations of this study. Second, we may not have studied a representative sample of our population, but it does provide useful information on which future investigations can be based.

In conclusion, with this study, we were able to document that psychological comorbidities are prevalent in patients with chronic LBP. Although the prevalence rates vary, anxiety, depression, disability, insomnia, and poor sleep quality were found in these patients. Substance (alcohol and tobacco) abuse also had a bearing on the pain as well as on these comorbidities. Patients with chronic pain frequently use alcohol as a pain-relieving agent and self-medication of depression, thus setting up a vicious cycle. Similarly, tobacco is used as a self-medication as an anxiolytic agent. ${ }^{41}$ We recommend that a "patient-centric" approach should be employed and potential comorbidities in all patients with chronic LBP should be explored and addressed to improve their quality of life and achieve a good clinical outcome.

\section{Conflict of Interest}

None declared.

\section{Acknowledgment}

This work was supported by the Indian Council for Medical Research (ICMR) (STS Reference ID: 2015-00825) as part of the ICMR short-term studentship program to the first author.

\section{References}

1 National Collaborating Centre for Primary Care (UK), Low Back Pain: Early Management of Persistent Non-specific Low Back Pain. London, United Kingdom: Royal College of General Practitioners; 2009

2 Hong JH, Kim HD, Shin HH, Huh B. Assessment of depression, anxiety, sleep disturbance, and quality of life in patients with chronic low back pain in Korea. Korean J Anesthesiol 2014;66(6):444-450

3 Kamal KC, Alexandru DO, Kamal D, et al. Managing low back pain in primary care. Curr Health Sci J 2020;46(4):396-404

4 Sharma R, ed Epidemiology of Musculoskeletal Conditions in India New Delhi, India: Indian Council of Medical Research (ICMR); 2012

5 Yu GZ, Ly M, Karim HT, Muppidi N, Aizenstein HJ, Ibinson JW. Accelerated brain aging in chronic low back pain. Brain Res 2021;1755:147263

6 Ong WY, Stohler CS, Herr DR. Role of the prefrontal cortex in pain processing. Mol Neurobiol 2019;56(2):1137-1166

7 Yang S, Chang MC. Chronic pain: structural and functional changes in brain structures and associated negative affective states. Int J Mol Sci 2019;20(13):3130

8 Thompson JM, Neugebauer V. Cortico-limbic pain mechanisms. Neurosci Lett 2019;702:15-23

9 Croft P, Rigby AS, Boswell R, Schollum J, Silman A. The prevalence of chronic widespread pain in the general population. J Rheumatol 1993;20(4):710-713

10 Liu $\mathrm{CH}$, Fu TS, Lee $\mathrm{CP}$, Hung CI. Reliability and validity of the Depression and Somatic Symptoms Scale among patients with chronic low back pain. Neuropsychiatr Dis Treat 2019;15:241-246

11 Jank R, Gallee A, Boeckle M, Fiegl S, Pieh C. Chronic pain and sleep disorders in primary care. Pain Res Treat 2017;2017:9081802

12 Marčić M, Mihalj M, Ivica N, Pintarić I, Titlić M. How severe is depression in low back pain patients? Acta Clin Croat 2014;53(3):267-271

13 Gebauer S, Scherrer JF, Salas J, Burge S, Schneider FD; Residency Research Network of Texas Investigators. Disability and disability benefit seeking in chronic low back pain. Occup Med (Lond 2015;65(4):309-316

14 Serbic D, Pincus T. Pain-related guilt in low back pain. Clin J Pain 2014;30(12):1062-1069

15 Artner J, Cakir B, Spiekermann JA, et al. Prevalence of sleep deprivation in patients with chronic neck and back pain: a retrospective evaluation of 1016 patients. J Pain Res 2013;6:1-6

16 O'Donoghue GM, Fox N, Heneghan C, Hurley DA. Objective and subjective assessment of sleep in chronic low back pain patients compared with healthy age and gender matched controls: a pilot study. BMC Musculoskelet Disord 2009;10:122

17 Khatua DK, Ghosh S, Mukhopadhyay DK, Goswami N, Pan PP, Palit AK. Psychological comorbidity of chronic low back pain. Indian J Phys Med Rehabil 2011;22:7-11

18 Pande KC. Psychological disturbance in Indian low back pain population. Indian J Orthop 2004;38:175

19 Levis B, Benedetti A, Thombs BD; DEPRESsion Screening Data (DEPRESSD) Collaboration. Accuracy of Patient Health 
Questionnaire-9 (PHQ-9) for screening to detect major depression: individual participant data meta-analysis. BMJ 2019;365:11476

20 Spitzer RL, Kroenke K, Williams JB, Löwe B. A brief measure for assessing generalized anxiety disorder: the GAD-7. Arch Intern Med 2006;166(10):1092-1097

21 Jensen MP, Chen C, Brugger AM. Interpretation of visual analog scale ratings and change scores: a reanalysis of two clinical trials of postoperative pain. J Pain 2003;4(7):407-414

22 Fairbank JC, Couper J, Davies JB, O'Brien JP. The Oswestry low back pain disability questionnaire. Physiotherapy 1980;66(8):271-273

23 Bressi C, Taylor G, Parker J, et al. Cross validation of the factor structure of the 20-item Toronto Alexithymia Scale: an Italian multicenter study. J Psychosom Res 1996;41(6):551-559

24 Smith S, Trinder J. Detecting insomnia: comparison of four self-report measures of sleep in a young adult population. J Sleep Res 2001;10(3):229-235

25 Backhaus J, Junghanns K, Broocks A, Riemann D, Hohagen F. Test-retest reliability and validity of the Pittsburgh Sleep Quality Index in primary insomnia. J Psychosom Res 2002;53(3):737-740

26 Soysal M, Kara B, Arda MN. Assessment of physical activity in patients with chronic low back or neck pain. Turk Neurosurg 2013;23(1):75-80

27 Adilay U, Guclu B, Goksel M, Keskil S. The correlation of SCL-90-R anxiety, depression, somatization subscale scores with chronic low back pain. Turk Neurosurg 2018;28(3):434-438

28 Jack K, McLean SM, Moffett JK, Gardiner E. Barriers to treatment adherence in physiotherapy outpatient clinics: a systematic review. Man Ther 2010;15(3):220-228

29 Tagliaferri SD, Miller CT, Owen PJ, et al. Domains of chronic low back pain and assessing treatment effectiveness: a clinical perspective. Pain Pract 2020;20(2):211-225

30 Polatin PB, Kinney RK, Gatchel RJ, Lillo E, Mayer TG. Psychiatric illness and chronic low-back pain. The mind and the spinewhich goes first? Spine 1993;18(1):66-71

31 Kamper SJ, Apeldoorn AT, Chiarotto A, et al. Multidisciplinary biopsychosocial rehabilitation for chronic low back pain: Cochrane systematic review and meta-analysis. BMJ 2015;350:h444

32 Joshi R, Santoshi JA, Rai N, Pakhare A. Prevalence and patterns of coexistence of multiple chronic conditions: a study from Indian urban outpatient setting. J Family Med Prim Care 2015;4(3):411-415

33 Pagé MG, Fortier M, Ware MA, Choinière $M$. As if one pain problem was not enough: prevalence and patterns of coexisting chronic pain conditions and their impact on treatment outcomes. J Pain Res 2018;11:237-254

34 Bener A, Verjee M, Dafeeah EE, et al. Psychological factors: anxiety, depression, and somatization symptoms in low back pain patients. J Pain Res 2013;6:95-101

35 Alsaadi SM, McAuley JH, Hush JM, et al. Detecting insomnia in patients with low back pain: accuracy of four self-report sleep measures. BMC Musculoskelet Disord 2013;14:196

36 Alsaadi SM, McAuley JH, Hush JM, Maher CG. Erratum to: Prevalence of sleep disturbance in patients with low back pain. Eur Spine J 2012;21(3):554-560

37 Ryder AG, Sunohara M, Dere J, Chentsova-Dutton YE, The cultural shaping of alexithymia In: Taylor GJ, Luminet O, Bagby RM, eds. Alexithymia: Advances in Research, Theory, and Clinical Practice. Cambridge: Cambridge University Press; 2018 33-48

38 Turesky DG. A Descriptive Analysis of Alexithymia among Patients with Chronic Back Pain [PhD (Doctor of Philosophy) thesis]. US: University of Iowa; 2011

39 Di Tella M, Castelli L. Alexithymia in chronic pain disorders. Curr Rheumatol Rep 2016;18(7):41

40 Rao D, Young M, Raguram R. Culture, somatization, and psychological distress: symptom presentation in South Indian patients from a public psychiatric hospital. Psychopathology 2007;40(5):349-355

41 Morissette SB, Tull MT, Gulliver SB, Kamholz BW, Zimering RT. Anxiety, anxiety disorders, tobacco use, and nicotine: a critical review of interrelationships. Psychol Bull 2007;133(2):245-272 